\title{
РЕСУРСНЫЙ ПОТЕНЦИАЛ НАУЧНЫХ УЧРЕЖДДЕНИЙ: ФАКТОРЫ, ВЛИЯЮЩИЕ НА ФОРМИРОВАНИЕ И РАЗВИТИЕ
}

\begin{abstract}
АНнОТАЦИЯ. Современная экономика характеризуется, прежде всего, уровнем научно-технических достижений и качеством научных результатов, играющих важную роль в состоянии отраслей. На сегодняшний день органы власти, органы управления наукой, организации коммерческого сектора все больше акцентируют свое внимание на сфере деятельности научных учреждений. Научные учреждения - это источники, производители новых знаний и технологий, являющихся значимыми для производства в целом. Степень обладания научным учреждением ресурсным потенциалом и его уровень становятся интересны различным участникам осуществления научной деятельности, представляемой в виде работ и услуг в сфере науки. Анализ современной экономической научной литературы свидетельствует об отсутствии единого мнения о понятии ресурсного потенциала научных учреждений. В статье дается авторское определение такого ресурсного потенциала. Подробно рассматриваются различные факторы, влияющие на ресурсный потенциал научных учреждений. Отдельно подчеркивается положительное и отрицательное влияние выявленных факторов.

кЛючевЫЕ СЛОВА. Ресурсный потенциал; научные учреждения; управление ресурсным потенциалом; сфера науки; реформа Российской академии наук.

ИНФОРМАЦИЯ О СТАТЬЕ. Дата поступления 28 октября 2016 г.; дата принятия к печати 16 ноября 2016 г.; дата онлайн-размещения 30 ноября 2016 г.
\end{abstract}

M. V. Kazarina

Baikal State University, Irkutsk, Russian Federation

\section{RESOURCE POTENTIAL OF SCIENTIFIC INSTITUTIONS: FACTORS AFFECTING ESTABLISHMENT AND DEVELOPMENT}

\begin{abstract}
Modern economy is characterized first of all by the level of scientific and technical achievements and the quality of scientific results playing a significant role in the state of the industries. At present, the authority bodies, the science management organs, organizations of the commercial sector more and more focus their attention on the sphere of scientific institution activities. The degree of possessing a resource potential on the part of the scientific institution is making various participants interested in performing scientific activities presented in form of works and services in the scientific sphere. Analysis of modern economic scientific literature testifies the absence of an integral opinion about the concept of resource potential of scientific institutions. The article gives the author's definition of such a resource potential. It considers in detail various factors that affect the resource potential of scientific institutions. Separately, it underlines the positive and negative impact of the identified factors.

KEYWORDS. Resource potential; scientific institutions; resource potential management; sphere of science; reform of the Russian Academy of Sciences.

ARTICLE INFO. Received October 28, 2016; accepted November 16, 2016; available online November 30, 2016.
\end{abstract}

\section{Baikal Research Journal}


Изучение сущности ресурсного потенциала и определение его состава применительно к научным учреждениям является актуальным в связи с проводимой реформой в сфере науки, реорганизацией и реструктуризацией имущественного комплекса Российской академии наук. Кроме этого, процесс реформирования совпал с постепенным переходом от экономики, которая основывалась на использовании природных ресурсов, к экономике, базирующейся на знаниях и новой информации [1, с. 11].

Незавершенность формирования подходов к природе ресурсного потенциала на различных уровнях экономики свидетельствует о недостаточной разработанности данного вопроса и отсутствия единого взгляда на проблему. Однако, обоснованное понимание сущности и назначения ресурсного потенциала, а также адекватное структурирование его состава способствует объективной оценке состояния ресурсного потенциала субъекта хозяйствования и его влияние на осуществление деятельности, в том числе на качественное и своевременное предоставление продукции.

В современной научной литературе выделяется ряд определений ресурсного потенциала (табл.).

Варианты трактовок понятия "ресурсный потенциал"

\begin{tabular}{|l|l|}
\hline \multicolumn{1}{|c|}{ Источник } & \multicolumn{1}{|c|}{ Определение } \\
\hline Анчишкин А.И. & $\begin{array}{l}\text { Набор средств, принимающих форму факторов производства в процессе } \\
\text { производства или предоставления услуг [2] }\end{array}$ \\
\hline Клейнер Г.Б. & $\begin{array}{l}\text { Совокупность находящихся в распоряжении предприятия «стратегических } \\
\text { ресурсов», которые имеют определенные значение для возможностей и } \\
\text { границ фунционирования предприятия в тех или иных условиях [3] }\end{array}$ \\
\hline Гончаров В.Н & $\begin{array}{l}\text { Совокупность ресурсов и производственных возможностей, приложимых } \\
\text { к достижению целей. В широком понимании означает возможности, } \\
\text { силы, запасы, средства, которые могут быть использованы, или уровень } \\
\text { мощности любого предприятия [4] }\end{array}$ \\
\hline Данилова А.С & $\begin{array}{l}\text { Совокупность ресурсов, объединенных под воздействием специфических } \\
\text { управленческих отношений, формирование которых обеспечивает } \\
\text { конкурентоспособность и стратегическое развитие предприятия [5] }\end{array}$ \\
\hline Кураленко О.Г & $\begin{array}{l}\text { Система материальных и нематериальных ресурсов предприятия, } \\
\text { используемых для того, чтобы произести совокупность товаров и услуг } \\
\text { в соответствии с потребностями потенциальных покупателей и его } \\
\text { стратегическими целями [6] }\end{array}$ \\
\hline $\begin{array}{l}\text { Мельник М.В., } \\
\text { Герасимова Е.Б. }\end{array}$ & $\begin{array}{l}\text { Совокупность ресурсов организации (трудовых и производственных), } \\
\text { обеспечивающих непрерывность и әффективность ее деятельности [7] }\end{array}$ \\
\hline
\end{tabular}

Анализ представленных в экономической литературе трактовок термина «ресурсный потенциал» позволил дать определение ресурсному потенциалу как совокупности материальных и нематериальных средств, которыми обладают учреждения в процессе своей деятельности для достижения своих целей [8].

Применительно к научному учреждению ресурсный потенциал можно определить как комплекс материальных и нематериальных ресурсов, включающих научный потенциал, необходимый и требующий постоянного наращивания и обновления для качественного и своевременного осуществления научной деятельности, предоставления научной продукции (работ и услуг в сфере науки).

Состояние ресурсного потенциала, которым обладает научное учреждение, в значительной степени определяет результативность научной деятельности и качество производимой им научной продукции. На формирование и развитие ресурсного потенциала научных учреждений влияет множество факторов, воздействие которых является разнонаправленным. К числу основных из них можно отнести следующие:

\section{Baikal Research Journal}

электронный научный журнал Байкальского государственного университета 
1. Экономическая ситуация. Проведение научных исследований требует больших затрат. Объем, структура и динамика финансирования оказывает прямое влияние на результативность деятельности научных учреждений [9, с. 4]. С одной стороны, в условиях низкого уровня финансирования научных организаций происходит сокращение затрат на оборудование, материалы, уменьшается количество работ на перспективу, происходит переход к выполнению краткосрочных проектов на основе уже имеющихся заделов. Серьезным испытаниям подвергается материально-техническая база науки. С другой стороны, низкая платежеспособность большинства хозяйствующих субъектов приводит к снижению спроса на научно-техническую продукцию со стороны промышленного производства и бизнес-предприятий [10]. Развитие ресурсного потенциала зависит от возможностей государства оказывать сфере науки экономическую поддержку.

2. Государственная политика в области науки. Состояние ресурсного потенциала учреждений науки во многом зависит от выбранных государством приоритетов научно-технической политики. Она определяет структуру (в том числе и территориальную) финансовой поддержки научных центров и институтов, выбор приоритетных направлений развития и разработки федеральных целевых программ.

3. Система законодательства. Этот фактор тесно связан с государственной политикой. Любые изменения в законодательстве влияют состояние ресурсного потенциала. Введенный в действие в 2013 г. закон «О контрактной системе в сфере закупок товаров, работ услуг для обеспечения государственных и муниципальных нужд» № 44-ФЗ привел к снижению уровня коррупции в области распределения государственных средств, к упорядоченности процесса приобретения товаров и услуг, к снижению монополизма поставщиков. Широкий резонанс в российских научных центрах вызвало изданное в 2016 г. распоряжение Федерального агентства научных организаций (ФАНО) о расторжении заключенных руководством центров договоров аренды земельных участков, являющих федеральной собственностью. В частности, в Иркутском научном центре (ИНЦ) ликвидируется множество торговых и социально-бытовых объектов, функционировавших на основе такой аренды. Соответственно ликвидация доходов от аренды снижает возможности развития и обновления ресурсного потенциала в ИНЦ.

4. Социальные тенденции в обществе. Современное снижение привлекательности и престижа научной деятельности также приводит к уменьшению ресурсного потенциала научного учреждения. Длительное недофинансирование институтов Российской академии наук (PAH), низкие заработные платы, невозможность проведения многих исследований привело к уходу ученых из науки, сделало их профессию непрестижной и в глазах многих - малоперспективной. Даже сегодняшнее увеличение финансирования в некоторых отраслях науки и предоставление новых возможностей не позволяет переломить данную тенденцию. Особо данная тенденция проявляется у молодежи, так называемое «поколение Y》 больше ориентировано на получение быстрого (даже не очень крупного) результата, чем на длительную работу для получения значимой отдачи, даже сулящей в отдаленной перспективе более высокую оплату труда. Такая ориентация по существу исключает стремление к научной деятельности. Массовый уход в 1990-х гг. молодых ученых из научных институтов и нашедших применение своей полученной ранее высокой квалификации в других сферах (в бизнесе, в образовании, в системе государственного управления и др.) не сопровождался их возвращением в науку в последующие более благоприятные годы $[11$, c. 111]. В результате в научных учреждениях образовался так называе-

\section{Baikal Research Journal}

электронный научный журнал Байкальского государственного университета 
мый «демографический провал», характеризующийся малочисленностью в возрастной структуре институтов ученых самого продуктивного среднего возраста, имеющих с одной стороны большой опыт проведения научных исследований и, с другой, перспективы дальнейшего результативной трудовой деятельности. Кроме этого, в научной среде наблюдается структурный дефицит кадров. Такое явление объясняется преобладанием специалистов нетехнических направлений, отсутствием различных стимулов поддержки выпускников и молодых специалистов, что определяет их отток за рубеж и высокий возрастной уровень профессионалов [12, с. 95].

5. Система управления. Существенное влияние на состояние и развитие ресурсного потенциала академического сектора науки имеют особенности системы управления научными учреждениями. Текущая реформа РАН привела к разделению управляющей подсистемы на два сегмента: Президиум Академии и Федеральное агентство научных организаций. Эти сегменты существенно различаются по своим целям, задачам, средствам и методам воздействия на управляемую подсистему. До настоящего времени не разработаны механизмы эффективной взаимосвязи управляющих сегментов системы управления, что приводит к разнонаправленности воздействий и ослаблению потенциала научных организаций. Решения ФАНО, обязательные для исполнения и ориентированные на эффективность использования имущественного комплекса, часто не согласуются с научными задачами и затрудняют их решение. Руководство РАН, утратившее в последние годы большую часть управленческих полномочий, часто не в состоянии способствовать развитию научных организаций и их потенциала. Разделение управляющей подсистемы на два сегмента привело к соответствующему разделению потока управляющих воздействий на две составляющие - воздействия на нематериальные элементы ресурсного потенциала, осуществляемые руководством Академии, и воздействия на материальные элементы, осуществляемые ФАНО. Это приводит к ослаблению связей между составляющими ресурсного потенциала как объектами управления, неравномерному их развитию, что неизбежно снижает целостность потенциала и синергетическое влияние элементов ресурсного потенциала на будущее развитие научных учреждений. Данная ситуация требует срочных и обоснованных решений, принимаемых на государственном уровне и направленных на повышение согласованности функций и полномочий органов, управляющих научными организациями.

6. Международное сотрудничество. Данный фактор, в отличие от других, имеет разнонаправленное воздействие на ресурсный потенциал научных учреждений. С одной стороны, расширение и усиление сотрудничества с учеными и научными организациями других стран позволяет повышать уровень квалификации ученых, знакомиться с новыми перспективными научными технологиями, выполнять исследования с помощью зарубежного оборудования, обмениваться знаниями, получать международные гранты, что в совокупности существенно повышает ресурсный потенциал. С другой стороны, активное международное сотрудничество повышает вероятность привлечения отечественных ученых к постоянной работе в зарубежных научных центрах. Такая «утечка мозгов» приводит к снижению ресурсного потенциала научных учреждений и эффективности его использования.

Выявленные факторы в той или иной степени могут быть отнесены и к образовательным организациям, схожие тенденции выявлены в работах [13; 14].

Совокупное влияние указанных факторов на формирование и развитие ресурсного потенциала научных учреждений показано на рисунке.

\section{Baikal Research Journal}

электронный научный журнал Байкальского государственного университета 


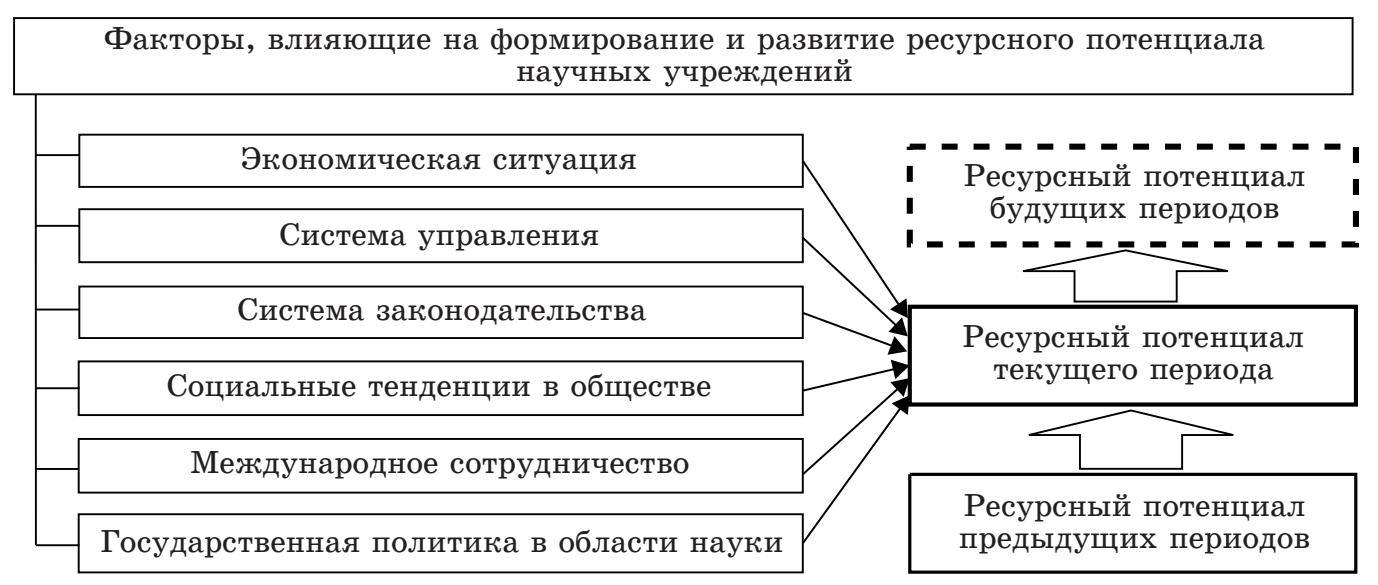

Факторы, усиливающие формирование и развитие ресурсного потенциала

Факторы, влияющие на формирование

и развитие ресурсного потенииала научных учреждений

Большинство рассмотренных факторов имеют позитивную связь с состоянием ресурсного потенциала. Улучшение характеристик этих факторов приводит к количественному и качественному развитию ресурсного потенциала, что требует их постоянного совершенствования. Двойственное влияние на ресурсный потенциал имеет фактор международного сотрудничества, однако, в сочетании с улучшением состояния других факторов возможно снижение или даже устранение его негативного воздействия. Так, расширение международного научного сотрудничества в условиях достаточного финансирования институтов, высокой оплаты труда квалифицированных ученых и престижа их профессии может не приводить к «утечке мозгов» за рубеж. При противоположном состоянии этих факторов влияние международного сотрудничества на ресурсный потенциал будет, скорее всего, отрицательным.

\section{Список использованной литературы}

1. Дресвянников В. А. Управление знаниями организации : учеб. пособие / В. А. Дресвянников. - М. : Кнорус, 2016. - 344 с.

2. Анчишкин А. И. Наука. Техника. Экономика / А. И.. Анчишкин. - М. : Экономика, 1986. -259 с.

3. Клейнер Г. Б. Стратегия предприятия / Г. Б. Клейнер. - М. : Дело, 2008. - 568 с.

4. Гончаров В. Н. Оценка ресурсного потенциала предприятий / В. Н. Гончаров, А. Ш. Шовкопляс, О. А. Шовкопляс // Экономические и социально-гуманитарные исследования. - 2016. - № 2 (10). - С. 66-69.

5. Данилова А. С. Стратегическое управление ресурсным потенциалом / А. С. Данилова // Актуальные проблемы авиации и космонавтики. - 2011. - Т. 2, № 7. - С. 129-131.

6. Кураленко О. Г. Ресурсный потенциал как основа инновационного развития предприятий / О. Г. Кураленко // Инновационная деятельность. - 2011. - № 3. - С. 37-40.

7. Мельник М. В. Анализ финансово-хозяйственной деятельности предприятия : учеб. пособие / М. В. Мельник, Е. Б. Герасимова. - М. : Форум : Инфра-М, 2007. - 192 с.

8. Казарина М. В. Научная деятельность и ее ресурсный потенциал / М. В. Казарина // Вестник Института дружбы народов Кавказа. Теория экономики и управления народным хозяйством. -2015 . - № 2 (34). - С. 32-36.

9. Казарина Л. А. Об услугах в сфере научного обслуживания / Л. А. Казарина // Сервис Plus. - 2016. - № 2. - С. 3-8.

\section{Baikal Research Journal}

электронный научный журнал Байкальского государственного университета 
10. Миндели Л. Проблемы финансирования российской науки [Электронный ресурс] / Л. Миндели, С. Черных // Институт проблем развития науки РАН : офиц. сайт. — Режим доступа: http://www.issras.ru/papers/sciec01_2009_Mindeli.php.

11. Ивашевский С. Л. Цели и средства развития российской науки / С. Л. Ивашевский // Вестник Нижегородского университета им. Н. И. Лобачевского. — 2012. — № 1. С. 110-113.

12. Владимирова О. Н. Проблемы инновационного развития регионов / О. Н. Владимирова, А. Т. Петрова // Always ahead facing the unknown : International Scientific and Practical Congress of Economists and Lawyers. Basel (Switzerland), October 9, 2014. — Basel (Switzerland) : Consilium, 2014. - P. 93-97.

13. Развитие высшего образования в России: тенденции, перспективы, инновации [подгот. С. В. Чупров, Л. В. Санина, Т. А. Лоскутова] // Известия Иркутской государственной экономической академии. - 2016. - T. 26, № 4. - C. 676-680. — DOI: 10.17150/25002759.2016(4).676-680.

14. Чупров С. В. Стратегические приоритеты развития научно-исследовательской деятельности вуза / С. В. Чупров, Л. В. Санина // Активизация интеллектуального и ресурсного потенциала регионов: новые вызовы для менеджмента компаний : материалы 2-й Всерос. конф. Иркутск, 19-20 мая 2016 г. / под науч. ред. С. В. Чупрова. - Иркутск : Изд-во Байкал. гос. ун-та, 2016. - С. 247-255.

\section{References}

1. Dresvyannikov V. A. Upravlenie znaniyami organizatsii [Management of the organization's knowledge]. Moscow, Knorus Publ., 2016. 344 p.

2. Anchishkin A. I. Nauka. Tekhnika. Ekonomika [Science. Technology. Economy]. Moscow, Ekonomika Publ., 1986. 259 p.

3. Kleiner G. B. Strategiya predpriyatiya [Enterprise's strategy]. Moscow, Delo Publ., 2008. 568 p.

4. Goncharov V. N., Shovkoplyas A. Sh., Shovkoplyas O. A. Assessment of enterprises' resource potential. Ekonomicheskie $i$ sotsial'no-gumanitarnye issledovaniya = Economical and Humanities Researches of the Regions, 2016, no. 2 (10), pp. 66-69. (In Russian).

5. Danilova A. Strategic management of resource potential. Aktual'nye problemy aviatsii $i$ kosmonavtiki $=$ Topical Issues of Airspace and Outer Space, 2011, vol. 2, no. 7, pp. 129-131. (In Russian).

6. Kuralenko O. G. Resource potential as a basis of innovative development of enterprises. Innovatsionnaya deyatel'nost' = Innovation Activity, 2011, no. 3, pp. 37-40. (In Russian).

7. Mel'nik M. V., Gerasimova E. B. Analiz finansovo-khozyaistvennoi deyatel'nosti pred priyatiya [Analysis of financial and economic activity of the company]. Moscow, Forum Publ., Infra-M Publ., 2007. $192 \mathrm{p}$.

8. Kazarina M.V. Scientific activity and its resource potential. Vestnik Instituta druzhby narodov Kavkaza. Teoriya ekonomiki i upravleniya narodnym khozyaistvom = Bulletin of Institute of Caucasus Peoples Friendship (Theory of Economy and Management of National Economy), 2015, no. 2, pp. 32-36. (In Russian).

9. Kazarina L. A., Kazarina M. V. On services in the field of scientific performance of services. Servis Plus, 2016, no. 2, pp. 3-8. (In Russian).

10. Mindeli L., Chernykh S. Problems of funding Russian science. Institut problem razvitiya nauki [Institute of Science Development Problems of the Russian Academy of Sciences]. Available at: http://www.issras.ru/papers/sciec01_2009_Mindeli.php. (In Russian).

11. Ivashevske S. L. Goals and means of developing Russian science. Vestnik Nizhegorodskogo universiteta im. N. I. Lobachevskogo = Bulltin of Lobachevsky University of Nizhny Novgorod, 2012, no. 1, pp. 110-113. (In Russian).

12. Vladimirova O. N., Petrova A. T. Problems of innovative regional development. Always ahead facing the unknown: International Scientific and Practical Congress of Economists and Lawyers. Basel (Switzerland), October 9, 2014. Basel (Switzerland), Consilium, 2014, pp. 93-97. (In Russian).

13. Chuprov S. V., Sanina L. V., Loskutova T. A. (eds). Development of higher education in Russia: trends, prospects, innovations. Izvestiya Irkutskoi gosudarstvennoi ekonomicheskoi

\section{Baikal Research Journal}


akademii $=$ Bulletin of Irkutsk State Economics Academy, 2016, vol. 26, no. 4, pp. 676-680. DOI: 10.17150/2500-2759.2016.26(4).676-680. (In Russian).

14. Chuprov S. V., Sanina L. V. Strategic priorities of developing university science and research activities. In Chuprov S. V. (ed.). Aktivizatsiya intellektual'nogo i resursnogo potentsiala regionov: novye vyzovy dlya menedzhmenta kompanii. Materialy 2 -i Vserossiiskoi konferentsii. Irkutsk, 19-20 maya $2016 \mathrm{~g}$. [Activating intellectual and resource potential of the regions: new challenges for company managers. Materials of the $2^{\text {nd }}$ All-Russian Research Conference. Irkutsk, May 19-20, 2016]. Irkutsk, Baikal State University Publ., 2016, pp. 247-255. (In Russian).

\section{Информация об авторе}

Казарина Марина Викторовна - преподаватель, кафедра менеджмента, маркетинга и сервиса, Байкальский государственный университет, 664003, г. Иркутск, ул. Ленина, 11, e-mail: arinzak.isea@yandex.ru.

\section{Author}

Marina V. Kazarina - Lecturer, Chair of Management, Marketing and Services, Baikal State University, 11 Lenin St., 664003, Irkutsk, Russian Federation; e-mail: arinzak.isea@yandex.ru.

\section{Библиографическое описание статьи}

Казарина М. В. Ресурсный потенциал научных учреждений: факторы, влияющие на формирование и развитие / М. В. Казарина // Baikal Research Journal. — 2016. — T. 7, № 6. - DOI: 10.17150/2411-6262.2016.7(6).13.

\section{Reference to article}

Kazarina M. V. Resource potential of scientific institutions: factors affecting establishment and development. Baikal Research Journal, 2016, vol. 7, no. 6. DOI: 10.17150/24116262.2016.7(6).13. (In Russian).

\section{Baikal Research Journal}

